\title{
Convective Initiation Ahead of the Sea-Breeze Front
}

\author{
Robert G. Fovell* and Peter S. Dailey** \\ ${ }^{*}$ University of California, Los Angeles $\quad{ }^{* *}$ AIR Worldwide, Boston, MA
}

\section{Introduction}

Fovell and Dailey (2001; "FD") used a high resolution 3D model to examine the interaction between the sea-breeze circulation (SBC) and horizontal convective rolls (HCRs) in a simplified dynamical framework roughly resembling Florida. The initial environmental flow was vertically sheared and directed parallel to an artificially straightened coastline. The inclusion of small perturbations on the land surface heat flux excited HCRs oriented parallel to the coastline by the early afternoon. The sea-breeze front (SBF) systematically encountered, and merged with, roll updrafts and downdrafts as it progressed inland.

FD's three simulations were a sea-breeze only (SBO) run resulting from flux perturbation removal, a rollonly (RO) run lacking the sea subdomain, and a Control run possessing both SBC and HCRs. Deep convection occurred only in the Control run; the SBO case developed only shallow cloudiness over the SBF and the RO run's rolls failed to bring air to saturation at all. Further, the Control run's deep convection was initiated, ostensibly by a roll, ahead of the SBF, and not as a consequence of a SBF-roll merger. Below, we discuss why this interesting and unanticipated result occurred.

\section{Comparison of the Control and SBO runs}

Figure 1 shows the Control run state at $27000 \mathrm{sec}$ (1:30 PM); all figures herein are oriented acrossshore and represent along-coastal averaged fields. Shallow cloudiness resided above the SBF which was in the process of approaching the first strong roll updraft of the early afternoon. The cloudiness above the roll was developing into deep convection at this time. Figure 2a shows the state at $24480 \mathrm{sec}$, shortly after the earliest time that this roll's cloud feature could be unambiguously discerned from the background moisture field. At this time, the incipient

${ }^{*}$ Corresponding author address: Prof. Robert Fovell, UCLA Atmospheric Sciences, Los Angeles, CA 900951565. E-mail: rfovell@ucla.edu cloud resided in a "tongue" of saturated air extending ahead of the SBF's frontal updraft. A very similar tongue appeared in the SBO run (Fig. 2b), showing it to be a consequence of the SBC.

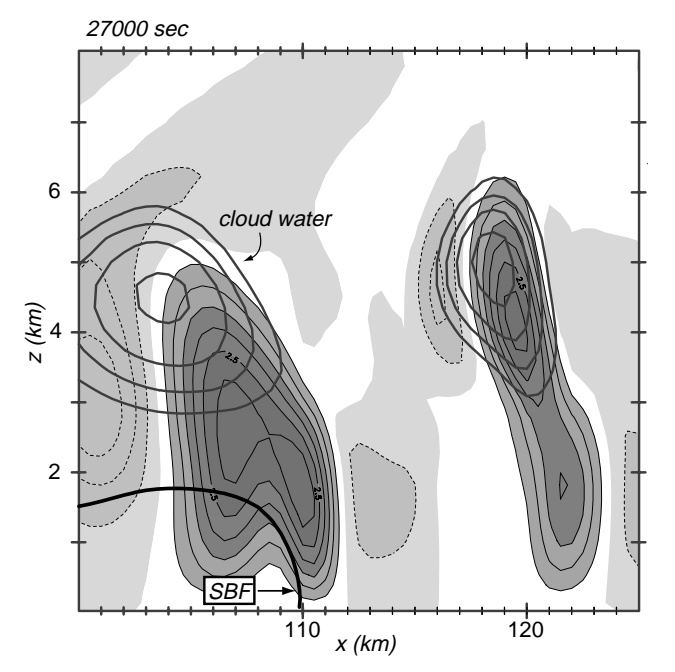

Figure 1: Control run vertical velocity (shaded with $0.5 \mathrm{~m} / \mathrm{s}$ contours) and cloud water $(0.5 \mathrm{~g} / \mathrm{kg}$ contours $)$ fields at $27000 \mathrm{sec}$. SBF kinematic boundary marked.

FD01 showed that once the roll cloud develops into deep convection, its influence on the SBF is profound. Figure $2 \mathrm{~b}$ emphasizes, however, that the Control and SBO runs were still quite comparable at this time, apart from the presence of the rolls over land. This motivated construction and examination of the difference fields shown in Figs. 2c and $3 \mathrm{a}$, created by subtracting SBO from Control run fields.

Naturally, as the SBO run reveals, SBC development constituted a substantial alteration to the upstream (over land) environment. The SBC induced horizontal across-shore flow directed away from (towards) the SBF in the lower (upper) troposphere along with gentle but extensive uplift in between (Fig. 3b). This lifting brought about the midtropospheric moistening represented by the humidity tongue. 

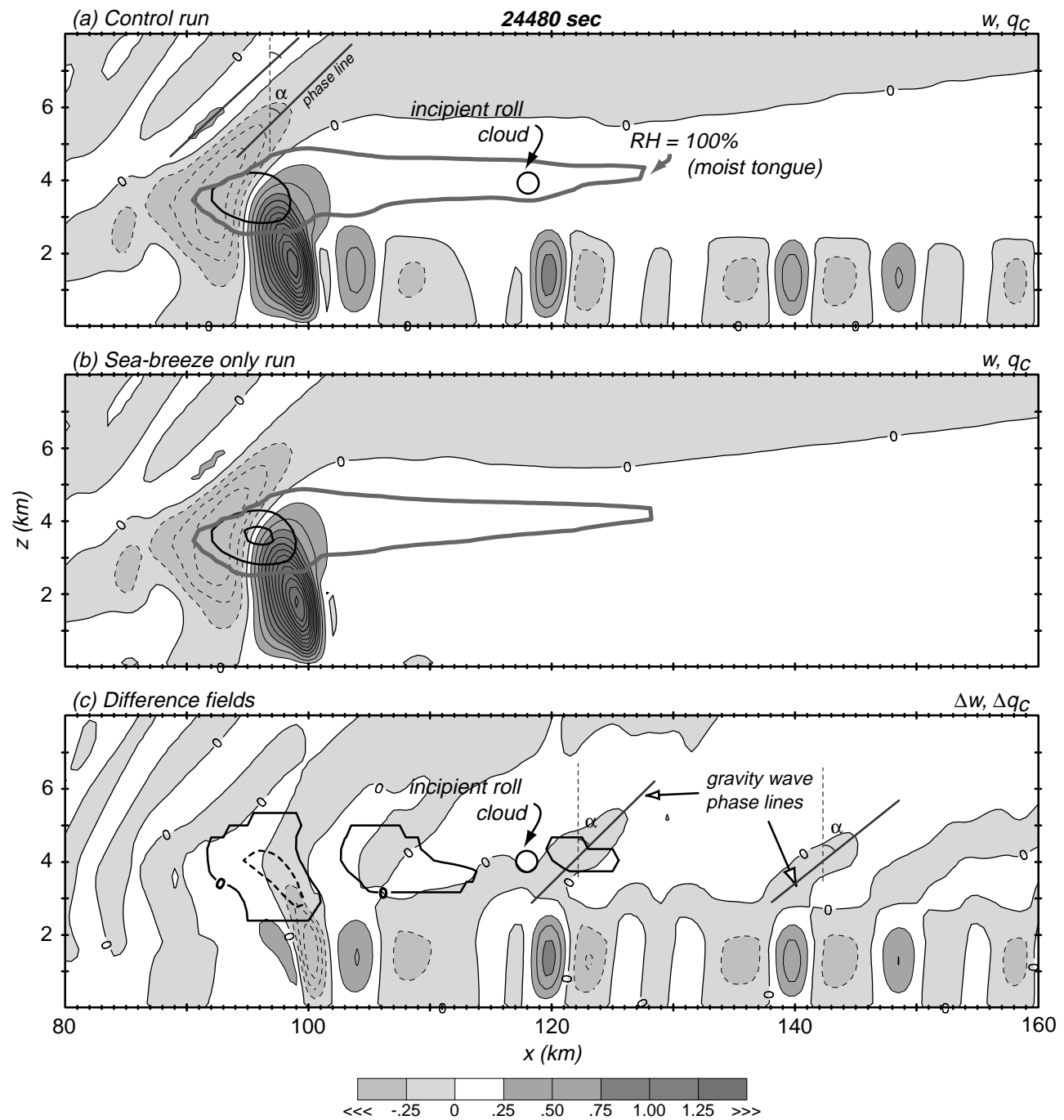

Figure 2: Vertical velocity (shaded with $0.25 \mathrm{~m} / \mathrm{s}$ contours) and cloud water fields at $24480 \mathrm{sec}$ for (a) the Control run and (b) the SBO run. Panel (c) shows the difference between the fields. Cloud water contour interval is $0.1 \mathrm{~g} / \mathrm{kg}$ in bottom panel; $0.5 \mathrm{~g} / \mathrm{kg}$ in others. 


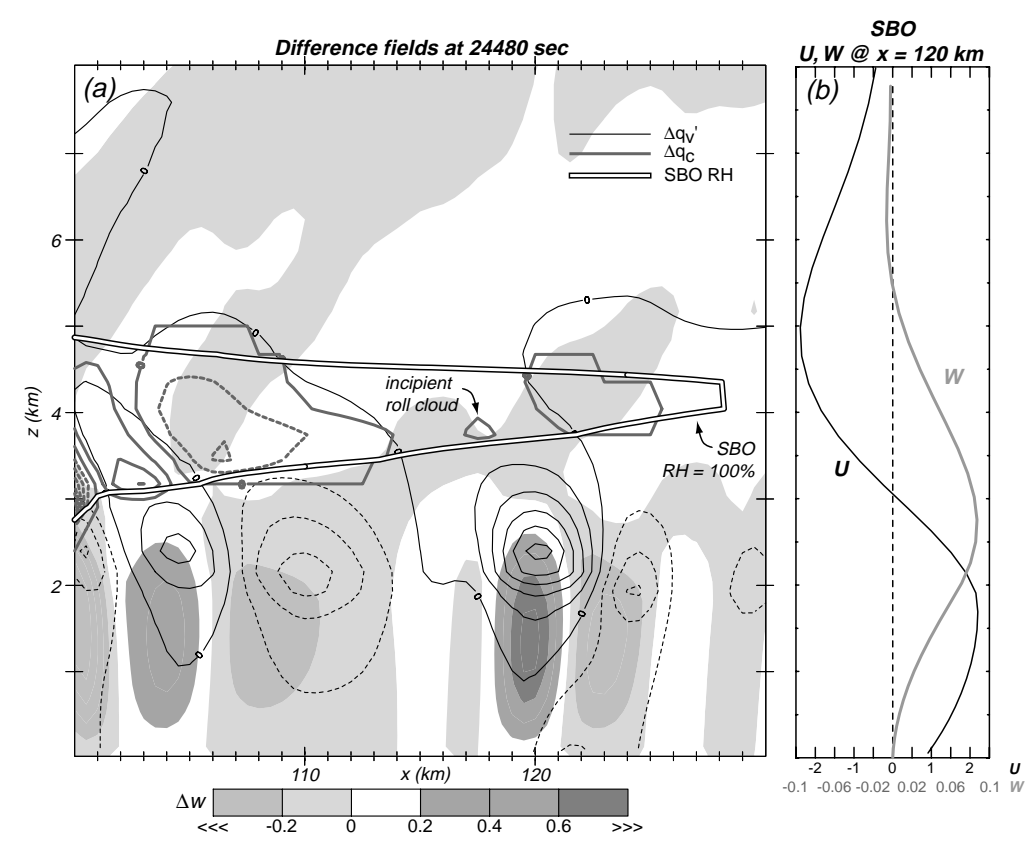

Figure 3: (a) Control-SBO difference fields at $24480 \mathrm{sec}$, showing vertical velocity (shaded) and contoured vapor $(0.01 \mathrm{~g} / \mathrm{kg})$ and cloud $(0.001 \mathrm{~g} / \mathrm{kg})$ fields; (b) representative upstream vertical profiles of horizontal and vertical velocity from the SBO run.

In turn, the Control-SBO differences emphasize how the rolls acted to modify the "background" SBC. The HCRs protruded vertically out of the mixed layer that they helped establish (along with subgrid scale mixing). The SBC-provided background flow there was directed offshore, towards the SBF. This resulted in the excitation of vertically propagating gravity waves through the "obstacle effect" (Clark et al. 1986) in the stable middle troposphere. As expected, the phase lines of these waves (sketched on Figs. 2c and 3) leaned upwind with height, and this resulted in the placement of wave-associated rising motion above and to the left (towards the SBF) of the roll updrafts. A simple oscillator model, not unlike that employed by Fovell et al. (1992), was used to verify this interpretation (not shown).

Since the gravity waves resided in an expansive area of gentle SBC-induced uplift (Fig. 3b), their vertical motions created regions with relatively stronger and weaker lifting than in the SBO simulation. Generally, larger (smaller) amounts of cloud water were found where the gravity waves strengthened (weakened) this background lifting, thereby placing the largest cloudiness enhancement above and to the left of the principal roll updraft where the incipient roll cloud was situated (Fig. 3a). The rolls also modified the upstream environment, including the midtroposphere, more directly by creating wa- ter vapor perturbations. Figure 3a reveals midtropospheric moistening above and to the left of the roll updrafts, transported upward by resolved lifting and subgrid mixing. These roll-induced "moist plumes" leaned towards the SBF with height, an advective consequence of the SBC-associated offshore flow.

\section{Discussion and conclusion}

Note that these two basically independent processes were having a synergistic effect. Further note quick growth of the incipient roll cloud followed immediately after the SBC-induced moist tongue's forward edge reached the location of enhanced moistening above the principal roll updraft. Thus, the rollinduced gravity waves and moisture plumes were acting in concert to create a preferred site for convective initiation within the midtropospheric moist tongue in advance of the $S B F$. The tongue appears to have been necessary to this result since convection was not initiated until the tongue moved over the roll. Yet, the absence of deep convection in the SBO run shows the SBC by itself was not enough. Moreover, the complete lack of cloudiness in the RO run - and above rolls located farther upstream in the Control case - demonstrates that, despite their strength, the rolls by themselves represented an insufficient triggering mechanism. 
Therefore, for the situation investigated herein, both SBC and HCR phenomena were necessary, and they combined to provoke deep convection ahead of the SBF. Interestingly, as shown by Fig. 4's backward trajectories, most (if not all) of the air in the early roll cloud was drawn from the midtroposphere and not from the roll updraft almost directly beneath. Certainly, the cloud did begin drawing in mixed layer air during its subsequent development into deep convection. It remains that during the crucial convective initiation phase, the roll's role was primarily an indirect one.

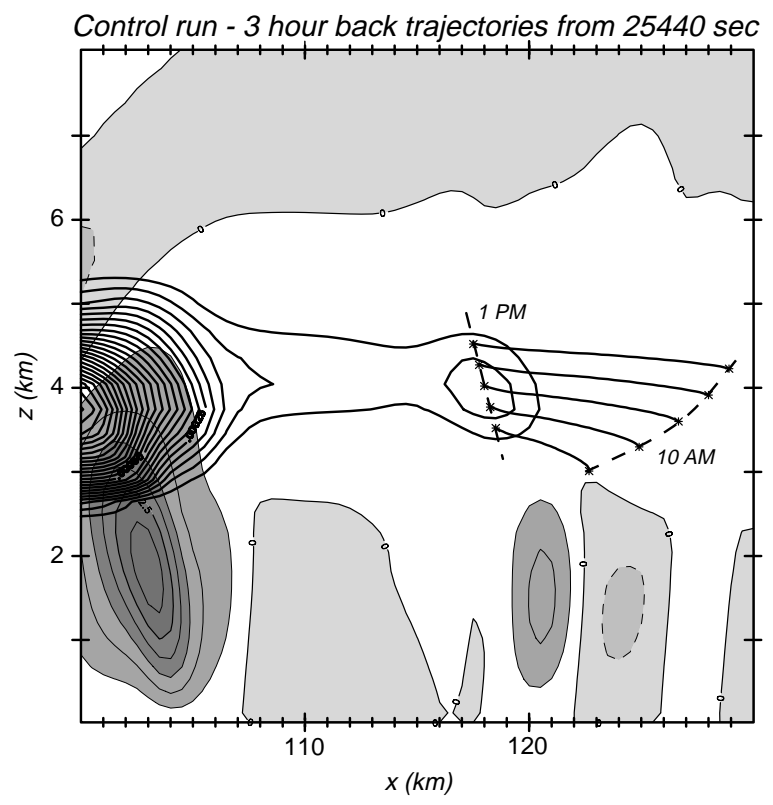

Figure 4: As in Fig. 1, but for the Control run at 25440 sec. Three hour backward trajectories show origins of roll cloud air. Cloud water contour interval $0.05 \mathrm{~g} / \mathrm{kg}$.

Figure 5 schematically summarizes our explanation for convective initiation ahead of the SBF. Figure 5a depicts the SBC's influence upon its upstream environment. The circulation consists of gentle uplift over an extended area reaching well inland, gradually yet systematically moistening the midtroposphere. This effect, resulting in what was termed the "moist tongue", is most pronounced and important in the SBF's immediate vicinity. The horizontal portion of this circulation consists of induced flow offshore (onshore) above (within) the boundary layer.

When boundary layer rolls develop (Fig. 5b), their overshooting into the stable midtroposphere creates an obstacle in the SBC-induced offshore flow there. Gravity waves are excited, producing vertical motions that can enhance or suppress cloudiness and moistening within the SBC tongue. The rolls also es-

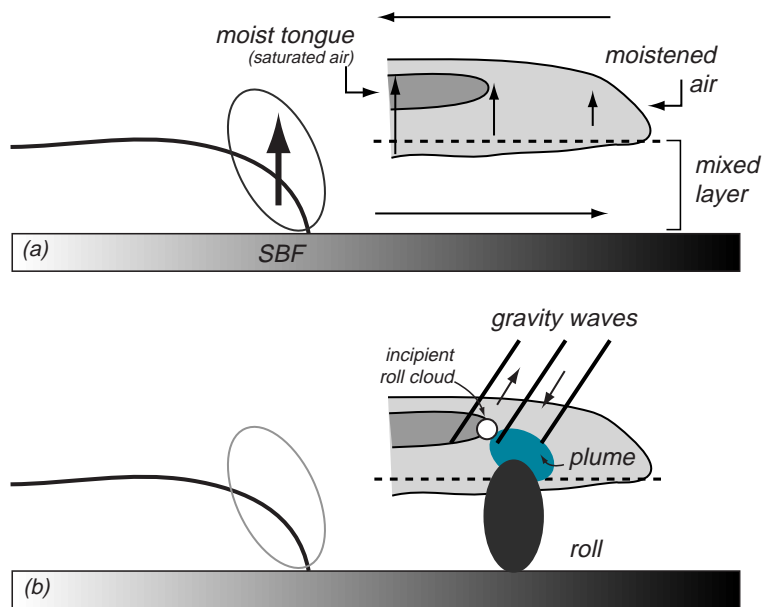

Figure 5: Schematic model of SBC and roll effects and interaction: (a) the SBC-induced circulation establishes midtropospheric offshore flow and also moistens that layer; (b) rolls act to further moisten portions of the midtroposphere through obstacle-type gravity wave disturbances and also advective effects. These combine to make a preferred site for convective initiation.

tablish moisture perturbations more directly by advecting vapor. In particular, moist plumes appear above the roll updrafts. In this case, the combination of gravity wave and moisture plume perturbations acting upon the moist tongue provided an irresistible spark for deep convection, one that did not exist until all of the elements were present and acting in concert.

\section{References}

Clark, T. L. T. Hauf and J. P. Kuettner, 1986: Convectively forced internal gravity waves: Results from two-dimensional numerical experiments. Quart. J. Roy. Meteor. Soc., 112, 899-925.

Fovell, R. D. Durran, and J. R. Holton, 1992: Numerical simulations of convectively generated stratospheric gravity waves. J. Atmos. Sci., 49, 14271442 .

Fovell, R. G. and P. S. Dailey, 2001: Numerical simulation of the interaction between the sea-breeze front and horizontal convective rolls. Part II: Alongshore ambient flow. Mon. Wea. Rev., 129, 2057-2072. 